\title{
JIMÉNEZ-YÁÑEZ, RICARDO-MARÍA (2020). COMUNICAR EN LA UNIVERSIDAD Y EN LA VIDA PROFESIONAL. PAMPLONA: EUNSA. 337 PÁGINAS
}

\author{
Blanca Gallostra Acín \\ Pontificia Universidad de la Santa Cruz \\ bgallostra@alumni.unav.es \\ https://orcid.org/0000-0003-1753-4722
}

Comunicar en la universidad y en la vida profesional es un libro que presenta una síntesis, clara y completa, sobre el discurso; especialmente el discurso académico y profesional, como bien indica el título. La adquisición de la competencia comunicativa es una tarea crucial en la etapa universitaria, como señala en el prólogo del libro la doctora Ruth Breeze, experta en Análisis del Discurso, Lingüística aplicada, Enseñanza de lenguas extranjeras y Escritura académica, y autora de numerosas obras académicas. Precisamente, el propósito del autor es atajar esta necesidad y proporcionar a estudiantes universitarios, y a cualquier otro lector, las herramientas necesarias para expresarse clara y efectivamente en la lengua española. Y más en el mundo en el que vivimos, en el que "the importance of developing critical cultural awareness in order to build effective intercultural relationships is undisputed in today's globalised world" (Breeze, 2017: 38).

Comunicar en la universidad y en la vida profesional está dividido en dos grandes partes: comunicación escrita y comunicación oral. Si bien de desigual extensión, puesto que la comunicación oral ocupa las últimas treinta páginas del volumen (comunicar con la palabra oral, pp. 303-331), muchos de los conceptos desarrollados antes son fácilmente extensibles a la comunicación oral, en especial lo referente a la elaboración de un buen discurso, puesto que un texto oral debe ser tan coherente y adecuado, por ejemplo, como un texto escrito.

En cuanto a los apartados sobre comunicación escrita, los primeros cubren reflexiones generales sobre la escritura y el discurso, de tal forma que introducen un marco de sentido para los siguientes apartados: la competencia comunicativa (pp. 17-20), propiedades de los textos (pp. 21-28), comunicar con la palabra escrita, reflexiones sobre la escritura (pp. 29-33), generación de ideas y el pensamiento crítico (pp. 35-39), apuntes sobre el pensamiento crítico (pp. 41-46). Los siguientes capítulos, pues, tratan ya propiamente de los elementos que logran que un texto comunique eficazmente: el párrafo (pp. 47-60), escritura coherente (pp. 61-76), el uso de los marcadores del discurso (pp. 77-83), cómo escribir bien un correo electrónico

Para citar esta reseña / To cite this book review: Gallostra Acín, Blanca (2020). Reseña de JiménezYáñez, Ricardo-María (2020): Comunicar en la universidad y en la vida profesional. Pamplona: Eunsa. 337 páginas. ELUA, 34: 227-231. https://doi.org/10.14198/ELUA2020.34.12

Enlace / Link: https://doi.org/10.14198/ELUA2020.34.12 
(pp. 85-88), una narración (pp. 89-92), una descripción (pp. 93-95), un diálogo (pp. 97-99), una exposición (pp. 101-106), una enumeración (pp. 107-112) y, por último, un extenso capítulo sobre cómo argumentar mejor (pp. 113-151). Los últimos apartados sobre el texto escrito abordan aspectos más materiales de la redacción de un texto: técnicas de revisión de un texto (p. 153), usos del castellano (pp. 155-255), léxico y estilo (pp. 257-276), escritura académica (pp. 277-287) y legibilidad: escribir textos fáciles de leer y comprender (pp. 289-301).

Ricardo Jiménez-Yáñez cuenta con una larga trayectoria docente e investigadora, durante la cual ha estudiado la persuasión y la expresión escrita y oral -Jiménez-Yáñez y Zárate, 2013; Jiménez-Yáñez, 2013; Jiménez-Yáñez, 2014; Jiménez-Yáñez, 2015; Jiménez-Yáñez, 2016 y Jiménez-Yáñez et alii, 2020-, y publicado un libro sobre el mismo tema, especializado en lenguaje jurista (Jiménez-Yáñez, 2016). La experiencia investigadora queda reflejada en la bibliografía de referencia utilizada en la elaboración del volumen, que incluye autores tanto del ámbito hispano como anglosajón y europeo, además de títulos que son ya clásicos de la comunicación y otros de publicación reciente. La variedad y amplitud de la bibliografía muestra, de nuevo, la virtud de esta monografía: ser una síntesis.

Por otro lado, los años de docencia se manifiestan tanto en el contenido como en la estructura del libro. La estructura, como hemos comentado, responde a una progresión temática que, al avanzar de lo general a lo específico, permite al lector tener un cuadro claro acerca de qué es un texto para entender cómo elaborarlo y por qué hacerlo así. Las herramientas propuestas no son vistas como un elenco de requisitos que debe reunir un buen texto, sino verdaderos instrumentos para la elaboración de un discurso. El lector, al tener claro qué es una buena redacción y qué no lo es, entiende la finalidad de los recursos propuestos, y por ello le será más fácil incorporarlos a su escritura. Esta progresión temática, pues, de lo más general a lo más específico, resulta muy didáctica.

Por lo que se refiere al contenido del volumen, la redacción cuenta con explicaciones claras y sintéticas, pero también con numerosos ejemplos y propuestas de ejercicios, para que el estudiante pueda no solo aprender, sino verdaderamente adquirir la competencia comunicativa. Cada apartado tiene una exposición de la teoría, que tiende a ser breve y sintética, con varias subdivisiones y epígrafes, de tal modo que cada principio o recurso estudiado quede, en cierta forma, resaltado autónomamente. Así, las diferentes ideas están verdaderamente diferenciadas y la lectura se hace ágil.

Intercalados con la teoría, hay varios ejemplos que la ilustran, tomados de otros autores, de la prensa, de la literatura, de alumnado, y también elaborados por el propio Jiménez-Yáñez. Son muy variados entre ellos, tanto por estilo como por extensión, según, por supuesto, qué pretenden ilustrar. De entre ellos, cabe destacar los ejemplos de textos completos, que dan un buen modelo al lector para entender qué hace de ellos un buen texto. Se encuentran, sobre todo, en los capítulos sobre cómo escribir una narración (pp. 89-92), cómo escribir una descripción (pp. 93-95), un diálogo (pp. 97-99), una exposición (pp. 101-106), una enumeración (pp. 107-112) y cómo argumentar mejor (pp. 113-151).

Por último, se encuentran los ejercicios, también repartidos a lo largo del libro. Normalmente se hallan al final de un apartado o subapartado, pero no en todos. Hay también de diversos tipos, como completar huecos, señalar usos acertados y erróneos de elementos del lenguaje, hallar la tesis, etc. Destacan, sin embargo, los ejercicios que requieren corregir y elaborar o reelaborar textos, ya que fomentan no solo recordar lo aprendido, sino criticar a partir de lo aprendido e incluso producir textos propios, actividades que 
desarrollan habilidades del pensamiento de orden superior y favorecen un aprendizaje profundo, no superficial, de la materia.

Entre los apartados del volumen de Jiménez-Yáñez, destacan tres de mayor extensión: cómo argumentar mejor (pp. 113-151), usos del castellano (pp. 155-255) y comunicar con la palabra oral (pp. 303-331). El primero de estos capítulos versa sobre la argumentación. En un volumen como este, dedicado al estudio del discurso universitario y profesional, no es de extrañar que la argumentación reciba un tratamiento especial. En efecto, la argumentación tiene como objetivo convencer al receptor de la propia tesis o, al menos, exponer los motivos que llevan a defenderla. Aprender a redactar un buen texto argumentativo es, pues, aprender a razonar, y ¿qué se espera de la universidad si no es aprender a pensar? JiménezYáñez, sin embargo, no se embarca en superfluos derroteros teóricos: su libro sigue la máxima de la eficacia. Por ello, el capítulo empieza ya con tres ejemplos de prensa de textos argumentativos, con una pequeña introducción, y solo después procede a exponer la teoría. Desde el principio, pues, el lector tendrá textos de referencia a la hora de ir desglosando, a medida que avanza el capítulo, qué compone un texto argumentativo. Entre esos elementos se encuentran los diferentes métodos discursivos de la argumentación: regla general, argumentos de experiencia, cita, figuras retóricas... cada uno de ellos seguido de al menos un ejemplo que muestre claramente cómo el autor utiliza ese mecanismo. Seguidamente, se presentan las características lingüísticas de la argumentación. A continuación, hay un epígrafe más extenso dedicado a pormenorizar los posibles procedimientos para elaborar la argumentación. Se distinguen las etapas generales (generación de ideas, planificación y redacción de la argumentación) y se proponen recursos detonantes de ideas, organizadores y de redacción que, junto con plantillas y ejercicios, resultan de suma utilidad. Por último, se incluyen numerosos ejemplos de textos argumentativos, tanto de estudiantes universitarios como de la prensa.

El siguiente capítulo de especial relevancia es el que se ocupa de los usos correctos del castellano. Es innegable que no son pocos los estudiantes universitarios que llegan a las aulas sin dominar el uso ortográfico y gramatical de la lengua española. Este dominio, sin embargo, es indispensable para poder redactar cualquier tipo de discurso escrito, e incluso oral. Es por eso que un libro dedicado a la comunicación en ámbito universitario no estaría completo, hoy día, si no contuviera el apartado del que estamos hablando. Además, la presentación de los diferentes temas es, siguiendo el estilo de Jiménez-Yáñez, muy clara y concreta. Hay siempre una breve explicación con ejemplos de las normas ortográficas o del uso gramatical de los signos de puntuación o ciertas palabras que suelen causar confusión (si no y sino, los porqués y el gerundio, entre otros), y seguidamente series de ejercicios para fijar los usos. Además, en algunos casos se detallan también usos incorrectos, pero frecuentes, de la lengua castellana, y se explica, comparando con el uso correcto, por qué no se debe escribir o hablar utilizando esas formas. Este capítulo, pues, servirá tanto de repaso general para reforzar el buen uso de la lengua como de consulta para aquellos lectores que tengan una duda específica o recurrente sobre algún aspecto concreto de la lengua castellana. Para ambos, la estructura del capítulo logra que el aprendizaje sea no solo fácilmente comprensible, sino ágil, efectivo y duradero.

Los tres siguientes apartados, léxico y estilo (pp. 257-276), escritura académica (pp. 277-287) y legibilidad: escribir textos fáciles de leer y comprender (pp. 289-301), resultan de especial interés al público general del volumen. Una vez cubierto lo necesario para el 
estudio del discurso en general y de la comunicación escrita, estos dos capítulos son de ayuda para perfeccionar los textos que el lector va a escribir con más frecuencia. De nuevo, la experiencia docente de Jiménez-Yáñez se traduce en unos capítulos cercanos al lector, puesto que el autor lo conoce bien: sus necesidades, dudas y fallos más frecuentes y, así, no se pierde en cavilaciones. Al contrario, en el capítulo de léxico, por ejemplo, expone los errores más comunes a la hora de escoger una palabra (verbos baúles, repeticiones, empleo impropio de parónimos), e incluye listas de ejemplos de todos ellos, así como ejercicios para poner en práctica los consejos. En el capítulo de escritura académica repasa sus características, contrastándolas con rasgos propios de textos más informales o literarios. El último de estos tres capítulos, sobre legibilidad, será seguramente del agrado de los lectores, pero más aún de los lectores de los lectores, si se me permite la licencia. El autor no escatima en herramientas para podar y ordenar un texto de tal forma que sea agradable y fácil leerlo, atributo que es más que valorado en cualquier tipo de texto, pero especialmente en el académico, puesto que la complejidad de la materia agradece la sencillez en la expresión. Parafraseando a Ortega, la claridad es la cortesía del escritor.

Por último, cabría destacar los hitos más notables del último capítulo: comunicar con la palabra oral (pp. 303-331). Como dice el mismo autor, comunicar oralmente, es decir, hablar en público, es una habilidad que no se aprende, sino que se adquiere, y se adquiere con la práctica. Por ello, el apartado da unas recomendaciones para expresarse con claridad y seguridad, tales como controlar los nervios y prestar atención al lenguaje paraverbal. A mi parecer, sin embargo, lo más enriquecedor para los estudiantes será la serie de actividades propuestas. Están pensadas con diferentes fines, desde pronunciar claramente cada palabra, controlar la entonación o hacer pausas. Cada una de las actividades o textos propuestos para leer en voz alta vienen introducidos con una explicación que informa al lector sobre el fin de dicha actividad y qué va a aprender con ella. Se trata de un capítulo sencillo, que guía a un lector no acostumbrado a ejercitarse en la competencia oral, a través de ejemplos de calidad (Lope de Vega y Azorín, entre otros) y ejercicios eficaces a la par que entretenidos (como leer trabalenguas en diferentes tonos de voz), para que logre una mejora significativa en su comunicación oral.

Así pues, Comunicar en la universidad y en la vida profesional es un libro que lleva a cabo lo que promete: enseñar a comunicar mejor académica y profesionalmente. Lo realiza a través de sus virtudes, que ya hemos enumerado anteriormente, y se resumen en ser una síntesis completa, clara y orientada al aprendizaje de las reglas fundamentales de la comunicación escrita y oral.

\section{REFERENCIAS BIBLIOGRÁFICAS}

Breeze, R. (2012). Rethinking academic writing pedagogy for the European university. Amsterdam: Rodopi.

Breeze, R. (2017). "Promoting critical cultural awareness in the international university". En Breeze, R. y Sancho-Guinda, C. (eds.). Essential competencies for English-medium university teaching, Cham: Springer.

Jiménez-Yáñez, R.-M. y Zárate-Rivero, B. (2013). "Estrategias de aprendizaje de expresión escrita para estudiantes de Derecho", Revista Lenguaje y textos, 37, pp. 83-90.

Jiménez-Yáñez, R.-M. (2013). “¿Se puede enseñar a persuadir con las señales del metadiscurso?”, Journal of Language and Law, 59, pp. 42-58. 
Jiménez-Yáñez, R.-M. (2014). "Metadiscurso y persuasión: estudio de editoriales de periódicos españoles sobre la muerte de Osama Bin Laden", Discurso \& Sociedad, 8(4), pp. 589-622.

Jiménez-Yáñez, R.-M. (2015). "An interview with Dr. Ruth Breeze and Dr. Florentina Taylor on foreign language teaching and learning", Bellaterra Journal of Teaching \& Learning Language \& Literature (BJTLLL), 8(3).

Jiménez-Yáñez, R.-M (2016). Escribir bien es de justicia. Cizur Menor: Aranzadi Thomson-Reuters. (2. ${ }^{\mathrm{a}}$ edición).

Jiménez-Yáñez, R.-M., Giner, D. y Franquet-Elía, P. (2020). "Estrategias retóricas de persuasión en Blogs Jurídicos (Blawgs) y Artículos Doctrinales", Discurso \& Sociedad, 15(2). (en prensa). 
